\title{
A Historical Perspective
}

\section{Diagnostic challenges in obstetrics and gynaecology in the pre sonology and cardiotocography era}

\author{
Malik Goonewardene ${ }^{a}$
}

Sonology and cardiotocography (CTG) were introduced to obstetrics and gynaecology in Sri Lanka at the Teaching Hospital Peradeniya in 1980. However both were not available in the Teaching Hospital Mahamodara Galle (THMG) until 1986. Diagnostic challenges faced by the author in the pre sonology and CTG era are presented.

\section{ESTABLISHING THE CAUSE OF A FETAL DEATH}

A 27 year old woman who had not received any antenatal care for her $2^{\text {nd }}$ pregnancy, was admitted to the academic obstetric unit of the THMG on the morning of $3^{\text {rd }}$ December 1982 at 34 weeks gestation, with significant lower abdominal pain of sudden onset since the previous evening. She appeared to have a tender uterus extending almost up to the xyphisternum but with ill-defined lateral margins. A death in utero was diagnosed with a Pinnard fetal stethoscope. Identification of fetal parts was difficult but the fetal head was thought to be in the right upper quadrant of the abdomen. She had mild pallor but was haemodynamically stable. The cervix was not effaced, the os was closed and there was no bleeding. She had a two year old son who had been delivered normally but 10 days later she had probably undergone an evacuation of retained products following a secondary postpartum haemorrhage ( no details were available). The tentative clinical diagnosis was placental abruption. A general surgeon excluded the need for any surgical intervention and agreed with conservative

${ }^{a}$ Senior Professor and Chair, Department of Obstetrics and Gynaecology, Medical Faculty, University of Ruhuna

Correspondence: Prof. Malik Gonnewardena MBBS MS FSLCOG FRCOG

Email-malikg@eureka.lk

Competing interests: Conflicts of interest none management and awaiting the spontaneous onset of labour. The next morning as she had still not established labour, a plain X-ray of abdomen (antero-posterior view) was carried out which confirmed the death in utero with marked over riding of skull bones ( Spalding's sign ), and also showed that the fetus was lying transversely in the upper part of the abdomen with its head in the right hypochondrial region. As the initial diagnosis was held in doubt, an exploratory laparotomy was carried out. A macerated fetus of 34 weeks gestation was found in the peritoneal cavity, with its placenta attached to the fundus of the 'post partum' uterus which had a transverse fundal rupture of approximately eight centimeters in length.. Approximately 300 $\mathrm{ml}$ of altered blood and meconium was found in the peritoneal cavity. The uterine rupture was repaired in two layers and she was transfused with $500 \mathrm{ml}$ of blood. She had an uncomplicated recovery. The spontaneous rupture of the uterus was presumed to be as a result of a weak scar on the fundus of the uterus, probably consequent to a uterine perforation during a probable evacuation of retained products after the previous normal delivery two years earlier.

\section{ESTABLISHING THE UNDERLYING CAUSE OF SUSPECTED HYPEREMESIS GRAVIDARUM IN A YOUNG GIRL}

On $30^{\text {th }}$ September 1983 a 14 year old girl who was virgo intacta, and denied any form of sexual contact, was admitted to the academic gynaecological unit of the THMG with episodes of vomiting following 17 weeks amenorrhoea, nine months after her menarche. She had an abdomino pelvic mass corresponding to a 16 weeks gravid uterus. Urinary human chorionic gonadotrophin (hCG) was > $700,000 \mathrm{iu} / \mathrm{L}$. In the absence of liquor on aspiration of the mass, an attempted radiological amniogram, using a contrast medium, showed a radio opaque mass with irregular outlines but no vesicles. A haemorrhagic, necrotic tumour about $25 \mathrm{~cm}$ in diameter, filling the Pouch of Douglas, the right fallopian tube overlying it and the uterus and the normal left adenaxae on its left, was found on exploratory laparotomy. There was no ascites or secondary deposits. The tumour was almost completely dissected out. Histopathology confirmed a pure chorio carcinoma. Post operatively she was treated with intravenous Methotrexate and Cyclophosphamide in the academic gynaecology unit itself, and she is quite well up to date. Taking into account the clinical and histopathological features, the tumour was considered to be a primary non gestational choriocarcinoma arising from the right ovary.

Both the above cases have been reported earlier ${ }^{1,2}$ but are briefly presented again to enable a comparison with the current methods of diagnosis with the aid of sonography and CTG. Spalding's sign is now observed by sonology and not by radiology and the absence of the fetal heart sounds is confirmed by a hand held Doppler fetal heart detector, CTG or sonology, and not by a Pinnard fetal stethoscope. Only semi-quantitative assays of urinary hCG were available then, using stepwise increasing dilutions of urine and a 'Gravindex Test' which had a sensitivity of only $3500 \mathrm{iu} / \mathrm{L}$. Amniograms are not carried out today to confirm trophoblastic tumors, because sonology is available.

\section{LOCALISATION OF THE PLACENTA PRIOR TO AMNIOCENTESIS.}

Prior to the sonology era, localizing the placenta prior to amniocentesis, to prevent inadvertent injury to the placenta during the insertion of the needle, was a challenge. The method adopted then was to: a) exclude a placenta praevia by the ability to palpate the fetal head directly 
through the vaginal fornices, b) identify the back of the fetus because the placenta would most likely be opposite to it, c) ensure that the bladder was empty, d) elevate the fetal head away from the pelvic inlet towards the umbilicus, in order to increase the volume of liquor in the 'forewaters' below the head, and e) to insert the amniocentesis needle in the midline immediately above the pubic symphysis ${ }^{3}$.

\section{ESTABLISHING LUNG MATURITY OF A FETUS PRIOR TO ELECTIVE, EARLY PRETERM DELIVERY}

Fetal lung maturity prior to elective preterm delivery could be predicted by using the foam stability test ('Shake or Bubble Test') ${ }^{4}$. This was a rapid and simpler method compared to the assessment of the Lecithin Sphingomyelin ratio, which required sophisticated and expensive biochemical techniques ${ }^{5}$. The amniotic fluid obtained by amniocentesis was serially diluted in normal saline, an equal volume of $95 \%$ ethanol added, shaken for 15 seconds, allowed to stand for 15 minutes, and examined for the presence of bubbles at the level of the meniscus. Absence of bubbles indicated a negative test while the positive results were graded according to the dilution at which bubbles persisted. Although antenatal corticosteroid therapy for impending preterm birth was being practiced, because surfactant therapy was not available in the THMG then, the foam stability test was useful in high risk women who required elective, early preterm delivery (between 28 -31 weeks gestation) and were unwilling to be transferred to Colombo for delivery.

Paradigm changes have occurred in the diagnosis of diseases, including obstetric and gynaecological problems, over the last four decades. Technological advances have contributed a great deal to these changes. A brief glimpse of the past has been provided. This may perhaps amuse the younger obstetricians and make them chuckle, while bringing nostalgic memories to those who are more senior.

\section{REFERENCES}

1. Goonewardene IMR . Spontaneous Rupture of Uterus. Case Records and Commentaries submitted for MS Obstetrics and Gynaecology, Postgraduate Institute of Medicine, Colombo 1983, Pg 222

2. Goonewardene M, Amaratunga K. Pure choriocarcinoma of ovary; probably non gestational in origin. Ceylon Medical Journal 1995; 40(1): 48.

3. Gorden HR, Deukmedjian AG. Suprapubic vs peri umbilical amniocentesis. Am J Obstet Gynecol 1975; 122: 287 - 292 .

4. Clements JA, Platzker AC, Tierney DF, et al. Assessment of the risk of respiratory distress syndrome by a rapid test for surfactant in amniotic fluid. New Engl J Med 1972; 286: 1077 1081

5. Gluck L, Kulowich MV. Lecithin / Sphingomyelin ratios in normal and abnormal pregnancy. Am J Obstet Gynecol 1973; 115: 639 - 646. 